\title{
Lung tissue mechanics in the early stages of induced paracoccidioidomycosis in rats
}

\author{
M.A. Shikanai-Yasuda ${ }^{1}$, \\ P.M. Pereira ${ }^{2}$, \\ E. Yamashiro-Kanashiro ${ }^{1}$, \\ M.I.S. Duarte' ${ }^{2}$ C.M. Assis ${ }^{1}$, \\ E.A. Geraldes ${ }^{1}$ and \\ P.H.N. Saldiva ${ }^{2}$
}

\author{
Departamentos de ${ }^{1}$ Doenças Infecciosas e Parasitárias and \\ 2Patologia, Faculdade de Medicina, Universidade de São Paulo, \\ São Paulo, SP, Brasil
}

\section{Correspondence \\ P.H.N. Saldiva \\ Departamento de Patologia \\ Faculdade de Medicina, USP \\ Av. Dr. Arnaldo, 455 \\ 01246-903 São Paulo, SP \\ Brasil \\ Fax: 55 (011) 3064-2744 \\ E-mail: pepino@usp.br}

Research supported by CNPq, FAPESP and LIM-HCFMUSP.

Received September 3, 1996

Accepted July 29, 1997

\begin{abstract}
Pulmonary dysfunction represents the most important cause of death in patients with paracoccidioidomycosis (PBM). In order to investigate the functional changes of the lungs in the early stages of PBM, a model of benign disease was developed by intratracheal challenge of 12-week old isogenic Wistar rats with 1 x $10^{6}$ yeast forms of Paracoccidioides brasiliensis. Animals were studied 30 and 60 days after infection, when fully developed granulomas were demonstrable in the lungs. Measurements of airway resistance, lung elastance and tissue hysteresis were made during sinusoidal deformations (100 breaths/ min, tidal volume $=2 \mathrm{ml}$ ) with direct measurement of alveolar pressure using the alveolar capsule technique. Infection caused a significant increase in hysteresis (infected: $1.69, \mathrm{~N}=13$; control: 1.13, $\mathrm{N}=12, \mathrm{P}=0.024$, ANOVA), with no alterations in airway resistance or lung elastance. Histopathological analysis revealed the presence of fully developed granulomas located in the axial compartment of the lung interstitial space. These results suggest that alterations of tissue mechanics represent an early event in experimental PBM.
\end{abstract}

Key words

- Experimental paracoccidioidomycosis

- Pulmonary mechanics

- Tissue mechanics

- Alveolar pressure

measurements

- Hysteresis

\section{Introduction}

Paracoccidioidomycosis is the most prevalent endemic mycosis in Latin America. Paracoccidioides brasiliensis is transmitted by the respiratory route through inhalation of conidia. Involvement of the phagocytic mononuclear system is the most common clinical finding in the acute form, mainly described in children or young adult patients. In contrast, the chronic form is prevalent in 30-50- year old adults with involvement of several organs, especially the lungs. Chronic granulomatous inflammation is a frequent histological finding, sometimes followed by intense fibrosis resulting in anatomical distortion of the oropharynx or upper respiratory tract $(1,2)$ or severe sequelae represented by lymph node or pulmonary fibrosis (3). Protein-losing enteropathy, as well as cellular and humoral immunodeficiencies, have been described as consequences of lymph node 
fibrosis (4). Besides this severe clinical evolution, another important cause of death is represented by cor pulmonale secondary to both obstructive and restrictive pulmonary insufficiency, which affects about $30 \%$ of chronic cases (5). Lung function has been studied only in the late stages of human paracoccidioidomycosis. The present study focuses on functional lung changes observed in the early phases of intratracheal paracoccidioidomycosis induced in isogenic rats.

\section{Material and Methods}

\section{Fungi}

Yeast forms of Paracoccidioides brasiliensis were obtained from 7-day old FavaNetto culture medium (6). Cell viability was at least $80 \%$, as assessed by Janus green staining (7). Total cell counts were performed with a hemocytometer chamber to estimate the inoculum size, which was $1 \times 10^{6}$ yeast forms of fungi $/ 0.5 \mathrm{ml}$ phosphate buffered saline.

\section{Rats}

A model of benign disease was developed by intratracheal challenge of twentyfive 12-week old isogenic Wistar-Furth rats. Animals were studied 30 and 60 days after infection. Corresponding groups injected with saline solution were used as controls.

\section{Histopathological study}

Histopathological studies were performed in three regions of the lungs: the perihilar area near the main bronchi, parenchyma including segmentary bronchi, and peripheral area usually with macroscopic alterations. Lymph nodes, liver, adrenals, kidney and brain were also studied. This analysis was done using paraffin-embedded slides stained with hematoxylin-eosin and by the GrocottGomori silver technique.

\section{Physiological measurements}

Rats were anesthetized with intraperitoneal sodium pentobarbital $(35 \mathrm{mg} / \mathrm{kg})$ and a polyethylene cannula was inserted into the trachea by direct visualization. The rats were ventilated with a rodent ventilator (Harvard 683, Harvard Apparatus Co., South Natik, $\mathrm{MA})$ at a constant tidal volume $(2.5 \mathrm{ml})$ with the respiratory frequency set at 100 breaths/ min. Airflow (V) was measured with a pneumotachograph connected to the tracheal cannula through a Valydine DP 45-16-2114 differential pressure transducer. Volume $(\mathrm{V})$ was obtained by electronic integration of the $\dot{V}$ signal. Tracheal pressure (Ptr) was measured with a Valydine DP 45-28-2114 differential pressure transducer. Positive end-expiratory pressure of $5 \mathrm{cmH}_{2} \mathrm{O}$ was used to maintain a functional residual capacity close to a normal value. Alveolar pressure (Palv) was measured according to the alveolar capsule technique described by Saldiva et al. (8). The capsules were made from 3-ml plastic syringes with the distal end cut off and connected to a Valydine DP 45-28-2114 differential pressure transducer through a 15$\mathrm{cm}$ long polyethylene catheter (1.6 mm ID). The pleural surface was punctured with an 18-gauge needle, and the capsule was glued to this surface with cyanoacrylate. The depth of the holes on the pleural surface was less than $0.5 \mathrm{~mm}$ to avoid sampling of bronchial pressures. A single capsule was used for each rat but placed at different sites in each animal.

Flow, Ptr and Palv signals were sampled at $200 \mathrm{~Hz}$ with a 12-bit analog-to-digital converter (DT-2801A, Data Translation, Marlboro, MA) and stored in a microcomputer. In each measurement, one data point was obtained by the average of 14-16 breaths.

Airway pressure (Paw) was obtained by subtracting Palv from Ptr. Airway resistance (Raw) was obtained by dividing Paw by $\dot{V}$ during lung inflation. Pulmonary dynamic 


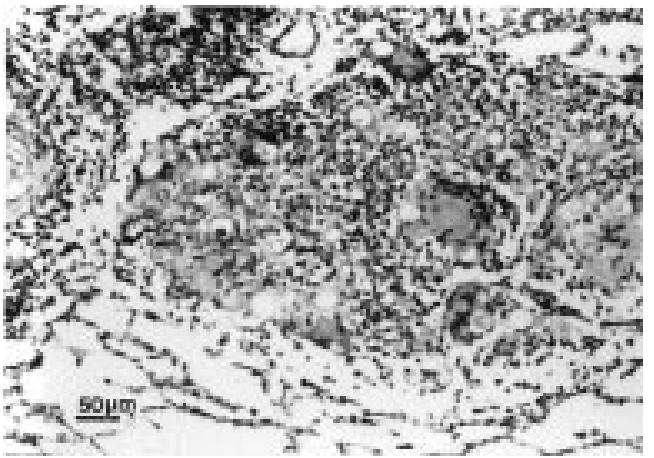

elastance (lung elastic modulus), tissue resistance and area of hysteresis of the pressure volume loop during tidal ventilation were obtained by the method of Fredberg and Stamenovic (9). Seven to eight breaths were averaged to complete the mechanical parameter for each animal.

\section{Statistical analysis}

The significance of the results was assessed by analysis of variance considering two factors, i.e., infection and time of infection. Variance of the parameters of interest was stabilized by applying logarithmic transformation of elastance, resistance and hysteresis.

\section{Results and Discussion}

The infection was limited to the lungs. Epithelioid granulomas rich in fungi (Figure 1, left) were observed in the lungs 15 to 150 days after the infection. Giant cells, macrophages and some polymorphonuclear cells, eosinophils and lymphocytes (Figure 1, right) were also found in the granulomas. Occasional necrosis was observed in a small number of granulomas during the period of follow-up.

Tables 1,2 and 3 show the mean and corresponding standard deviation (SD) of functional variables for hysteresis, elastance and resistance, respectively, measured for each period of time, as well as the corresponding output of ANOVA analysis for each variable.

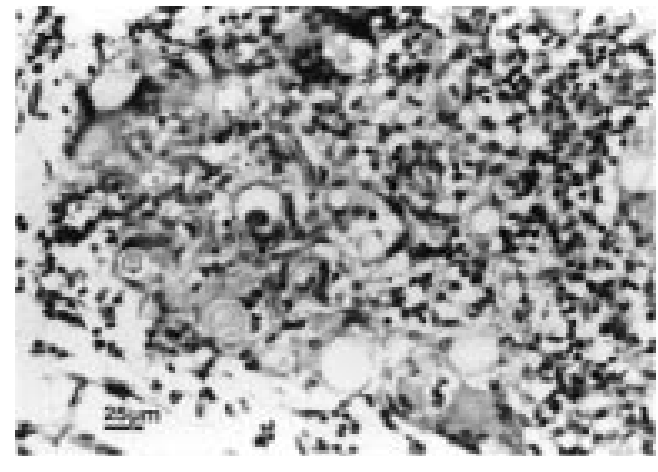

Figure 1 - Compact granulomas in the lungs of Wistar rats 60 days after inoculation with $P$. brasiliensis (hematoxylin and eosin, left $=$ 200X, right $=400 \mathrm{X}$.
Table 1 - Effect of paracoccidioidomycosis infection on pulmonary hysteresis.

$P=0.024$, significance of paracoccidioidomycosis infection (ANOVA). $P=0.491$ and $P=0.174$, time of infection and interaction infection vs time (not significant, ANOVA).

\begin{tabular}{lccc}
\hline & \multicolumn{3}{c}{ Hysteresis $\left(\mathrm{cmH}_{2} \mathrm{O} / \mathrm{ml}\right)$} \\
\cline { 2 - 4 } & 30 days & 60 days & Total \\
\hline Control & & & \\
Mean & 0.76 & 1.39 & 1.13 \\
Median & 0.75 & 1.16 & 0.88 \\
Standard deviation & 0.26 & 0.99 & 0.81 \\
Minimum & 0.50 & 0.51 & 0.50 \\
Maximum & 1.09 & 3.34 & 3.34 \\
No. of cases & 5 & 7 & 12 \\
Infected & & & \\
Mean & 1.79 & 1.61 & 1.69 \\
Median & 1.50 & 1.66 & 1.54 \\
Standard deviation & 0.79 & 0.88 & 0.80 \\
Minimum & 0.87 & 0.68 & 0.68 \\
Maximum & 2.82 & 3.23 & 3.23 \\
No. of cases & 6 & 7 & 13 \\
Total & & & \\
Mean & 1.32 & 1.50 & 1.42 \\
Median & 1.09 & 1.40 & 1.16 \\
Standard deviation & 0.78 & 0.90 & 0.84 \\
Minimum & 0.50 & 0.51 & 0.50 \\
Maximum & 2.82 & 3.34 & 3.34 \\
No. of cases & 11 & 14 & 25 \\
& & &
\end{tabular}

Increased hysteresis $(\mathrm{P}=0.024)$ was observed in infected animals at 30 and 60 days after inoculation compared to control animals. No difference in elastance or resistance was observed between groups during either period of infection.

In human paracoccidioidomycosis, initial involvement of the lungs may occur at 
Table 2 - Paracoccidioidomycosis (PBM) infection has no effect on pulmonary elastance.

Neither PBM infection $(P=0.283)$, time of infection $(P=0.496)$ nor interaction infection $v s$ time $(P=0.561)$ were statistically significant (ANOVA).

\begin{tabular}{|c|c|c|c|}
\hline & \multicolumn{3}{|c|}{ Elastance $\left(\mathrm{cmH}_{2} \mathrm{O} / \mathrm{ml}\right)$} \\
\hline & 30 days & 60 days & Total \\
\hline \multicolumn{4}{|l|}{ Control } \\
\hline Mean & 2.37 & 2.91 & 2.68 \\
\hline Median & 2.19 & 3.35 & 2.72 \\
\hline Standard deviation & 0.81 & 0.92 & 0.88 \\
\hline Minimum & 1.67 & 1.13 & 1.13 \\
\hline Maximum & 3.73 & 3.79 & 3.79 \\
\hline No. of cases & 5 & 7 & 12 \\
\hline \multicolumn{4}{|l|}{ Infected } \\
\hline Mean & 2.99 & 3.09 & 3.04 \\
\hline Median & 2.83 & 3.18 & 3.05 \\
\hline Standard deviation & 0.82 & 1.02 & 0.90 \\
\hline Minimum & 2.10 & 1.80 & 1.80 \\
\hline Maximum & 4.00 & 4.38 & 4.38 \\
\hline No. of cases & 6 & 7 & 13 \\
\hline \multicolumn{4}{|l|}{ Total } \\
\hline Mean & 2.71 & 3.00 & 2.87 \\
\hline Median & 2.38 & 3.27 & 3.05 \\
\hline Standard deviation & 0.84 & 0.94 & 0.89 \\
\hline Minimum & 1.67 & 1.13 & 1.13 \\
\hline Maximum & 4.00 & 4.38 & 4.38 \\
\hline No. of cases & 11 & 14 & 25 \\
\hline
\end{tabular}

the alveolar or interstitial level, as a granulomatous or an exudative pattern, which usually does not lead to abnormalities in spirographic tests. As a consequence of lymphatic spreading of the lesions along the peribronchial tissue, centrifugal histological changes are commonly observed. These findings, sometimes with simultaneous fibrosis and alveolar destruction, may be responsible for the functional disturbances observed in patients with chronic pulmonary paracoccidioidomycosis (10). Obstruction and restriction have been the most frequent spirographic patterns described in these patients.

Similarly to the human disease, hamsters infected by the intratracheal route presented with hilar bronchial involvement with centrifugal dissemination after regional lymph
Table 3 - Paracoccidioidomycosis (PBM) infection has no effect on pulmonary resistance.

Neither PBM infection $(P=0.098)$, time of infection $(P=0.609)$ nor interaction infection $v s$ time $(P=0.993)$ were statistically significant (ANOVA).

\begin{tabular}{lccc}
\hline & \multicolumn{3}{l}{ Resistance $\left(\mathrm{cmH}_{2} \mathrm{O} \mathrm{ml}^{-1} \mathrm{~s}^{-1}\right)$} \\
\cline { 2 - 4 } & 30 days & 60 days & Total \\
\hline Control & & & \\
Mean & 0.047 & 0.058 & 0.053 \\
Median & 0.033 & 0.037 & 0.035 \\
Standard deviation & 0.057 & 0.052 & 0.052 \\
Minimum & 0.002 & 0.013 & 0.002 \\
Maximum & 0.143 & 0.160 & 0.160 \\
No. of cases & 5 & 7 & 12 \\
Infected & & & \\
Mean & & & \\
Median & 0.085 & 0.097 & 0.091 \\
Standard deviation & 0.083 & 0.073 & 0.080 \\
Minimum & 0.019 & 0.065 & 0.054 \\
Maximum & 0.150 & 0.000 & 0.000 \\
No. of cases & 6 & 7 & 0.190 \\
Total & & & 13 \\
Mean & 0.068 & 0.077 & 0.073 \\
Median & 0.067 & 0.064 & 0.067 \\
Standard deviation & 0.051 & 0.060 & 0.055 \\
Minimum & 0.002 & 0.000 & 0.000 \\
Maximum & 0.150 & 0.190 & 0.190 \\
No. of cases & 11 & 14 & 25 \\
& & &
\end{tabular}

node involvement by confluent granulomas (11). These changes might represent lesions which could later evolve to fibrosis. An experimental model more similar to human pulmonary fibrosis seems to be represented by mice intranasally inoculated with conidia, as described by Restrepo et al. (12). However, an intriguing difference between experimental and human pulmonary disease is the long period of time between the initial infection and the development of chronic disease in human paracoccidioidomycosis.

We suggest that benign mycosis in isogenic Wistar-Furth rats provides a useful model to study changes in lung function during the early phases of paracoccidioidomycosis, mainly due to the presence of predominantly cellular granulomas in response 
to the infectious agent and the absence of significant scarring. As a consequence of the granulomatous infection, a significant increase in hysteresis $(\mathrm{P}=0.024)$ was observed at 30 days, which remained elevated up to the end of the experiment (60 days). The present study represents the first description of increased tissue resistance independent of bronchoconstriction. Histopathological examination performed in three different areas of the lung at day 30 and 60 after the infection showed fully developed granu- lomas only in infected rats. These results indicate that changes in tissue mechanics due to granuloma formation along the axial compartment of lung connective tissue are an early event in experimental paracoccidioidomycosis. In addition, it is probable that the granuloma may act as a viscous or plastic element in the pulmonary interstitium causing an increase of tissue pressure losses at the tissue level, which probably precedes the restrictive and/or obstructive functional patterns observed in chronic human disease.

\section{References}

1. Machado Filho J, Miranda JL \& Teixeira GA (1965). Das sequelas da blastomicose sul americana. O Hospital, 68: 1346-1354.

2. Pereira JL \& Silva AP (1982). The correction of microstomia following South American blastomycosis: A case report. British Journal of Plastic Surgery, 35: 204205.

3. Andrade DR, Hutzler RU, Carvalho SA, Rosenthal C, Carvalho MAB \& Ferreira JM (1976). Hipoproteinemia em pacientes com paracoccidioidomicose do tubo digestivo e sistema linfático abdominal. Revista do Hospital das Clínicas da Faculdade de Medicina de São Paulo, 31 : 174-179.

4. Shikanai-Yasuda MA, Segurado AAC, Pereira-Pinto W, Nicodemo AC, Sato M, Duarte AJS, Del Negro GB, Hutzler RU, Shiroma M \& Amato-Neto $V$ (1992). Immunodeficiency secondary to juvenile paracoccidioidomycosis: associated infections. Mycopathologia, 120: 23-28.
5. Ratto OR \& Afonso JE (1994). Pulmonary lesions: clinical and functional aspects. In: Franco MF, Lacaz CS, Restrepo-Moreno A \& Del Negro G (Editors), Paracoccidioidomycosis. CRC Press, Boca Raton, 271278.

6. Fava Netto C, Vegas VS, Sciannaméa IM \& Guarnieri DB (1969). Antígeno polissacarídeo do Paracoccidioides brasiliensis, necessário ao preparo do antígeno. Revista do Instituto de Medicina Tropical de São Paulo, 11: 177-181.

7. Berliner MD \& Reca ME (1966). Vital staining of $H$. capsulatum with Janus green $B$. Sabouraudia, 5: 26-29.

8. Saldiva PHN, Zin WA, Santos RLB Eidelman DH \& Milic-Emili J (1992). Alveolar pressure measurement in openchest rats. Journal of Applied Physiology, 72: 302-306.
9. Fredberg DF \& Stamenovic D (1989). On the imperfect elasticity of lung tissue. Journal of Applied Physiology, 67: 24082419.

10. Tuder RM, El Ibrahim R, Godoy CE \& De Britto T (1985). Pathology of human pulmonary paracoccidioidomycosis. Mycopathologia, 92: 179-188.

11. Tani EM, Franco MF, Peraçoli MTS \& Montenegro MR (1987). Experimental pulmonary paracoccidioidomycosis in the Syrian hamster: morphology and correlation of lesion with immune response. Journal of Medical and Veterinary Mycology, 25: 291-300.

12. Restrepo $S$, Tobon A, Trujillo J \& Restrepo A (1992). Development of pulmonary fibrosis in mice during infection with Paracoccidioides brasiliensis conidia. Journal of Medical and Veterinary Mycology, 30: 173-184. 